\title{
IMPACT OF EXERCISE-BASED CARDIAC REHABILITATION ON ATTITUDE TO THE THERAPY, AIMS IN LIFE AND PROFESSIONAL WORK IN PATIENTS AFTER MYOCARDIAL INFARCTION
}

\author{
Iwona Korzeniowska-Kubacka ${ }^{1}$, Maria Bilińska ${ }^{2}$, Dorota Piotrowska ${ }^{1}$, Jadwiga Wolszakiewicz ${ }^{1}$, \\ Ryszard Piotrowicz ${ }^{1}$
}

Institute of Cardiology, Warsaw, Poland

${ }^{1}$ Department of Cardiac Rehabilitation and Noninvasive Electrocardiology

${ }^{2}$ Department of Arrhythmia

\begin{abstract}
Background: Comprehensive cardiac rehabilitation aims to restore pathophysiological and psychosocial consequences of myocardial infarction (MI). The aim of the study was to assess how exercise-only-based cardiac rehabilitation (ECR) influences the attitude to the therapy (ATT), to the aims in life and professional work (AAL) amongst men and women after MI. Material and Methods: The study comprised 44 post-MI patients: 28 men and 16 women, mean age $58 \pm 10$ years old, referred to ECR. Patients underwent 24 interval cycle ergometer trainings 3 times a week. At the beginning and after the training program (TP) each patient underwent exercise stress test (EST) and was scored to ATT and ALL based on the Psychological Effects of Rehabilitation Score Scale (PERSS) according to Tylka and Makowska. The analysis covered: 1) EST findings: maximal workload and test duration (min), 2) ATT and AAL based on PERSS, 3) resuming professional work. Results: Exercise capacity improved significantly after TP. Attitude to the aims in life and professional work significantly increased in the whole group $(4.4 \pm 2.8 \mathrm{vs} .5 .1 \pm 2.4, \mathrm{p}<0.01)$ and separately in men (4.5 \pm 2.9 vs. $5.1 \pm 2.5, \mathrm{p}<0.05)$ and women $(4.3 \pm 2.6$ vs. $5.0 \pm 2.0, \mathrm{p}<0.05)$. Attitude to the therapy did not change significantly in the whole group (5.6 \pm 2.8 vs. $6.0 \pm 2.8)$ and in men (5.9 \pm 2.9 vs. $6.0 \pm 2.9)$, but increased significantly in women $(5.0 \pm 2.5$ vs. $6.1 \pm 2.7$, p $<0.05)$. Professional work was resumed, averagely by $86.4 \%$ of all patients ( $85.7 \%$ men and $87.5 \%$ women). Conclusions: Physical training beneficially influenced post-MI men's and women's attitude to the aims in life, professional work and attitude to the therapy in women. Med Pr. 2019;70(1):1-7
\end{abstract}

Key words: return to work, cardiac rehabilitation, physical training, post-MI patients, attitude to the therapy, attitude to the aims in life and professional work

Corresponding author: Iwona Korzeniowska-Kubacka, Institute of Cardiology, Department of Cardiac Rehabilitation and Noninvasive Electrocardiology, Alpejska 42, 04-628 Warsaw, Poland, e-mail: drkubacka@wp.pl

Received: October 5, 2017, accepted: July 5, 2018

\section{INTRODUCTION}

Cardiac rehabilitation (CR) is a comprehensive program composed of physical training, psychological intervention, education and counseling to reduce cardiac risk for patients with cardiovascular diseases [1-3]. Cardiac rehabilitation participation is not only associated with increased exercise capacity, improved diet, smoking cessation, but also with improvements in psychosocial well-being [4]. Recently, lower anxiety and depression symptoms have been reported for cardiac patients attending exercise-only-based CR programs [5]. Apart from the benefits mentioned above, return to work has been recognized as the most important indicator of $\mathrm{CR}$ efficacy [6,7].
It is noteworthy that developments in the management of acute myocardial infarction (MI), including direct percutaneous coronary intervention (PCI), did not improve returning to work. Previous estimates of return to work after MI ranged $72-92 \%$, and did not change over 20 years $[8,9]$. It is likely, that factors other than technical progress have an impact on returning to professional work [10-12]. This study has been designed to test whether participation in the physical training program, without psychological support, influences psychosocial well-being in a heterogenous group of patients after MI. Special attention was focused on female patients because of the limited number of studies assessing the effectiveness of CR for women [13]. 
Authors have hypothesized that post-MI patients engaged in the training program have a better attitude to the therapy (ATT), to the aims in life and professional work (AAL). The literature available contains no reports on this issue.

\section{MATERIAL AND METHODS}

The study comprised 44 consecutive post-MI patients ( 28 men and 16 women), aged $58 \pm 10$ years old, who were referred to the second phase of CR.

Inclusion criteria were: age $\leq 65$ years old, sinus rhythm, preserved left ventricular function (ejection fraction $\geq 50 \%$ ), clinical stability for at least 2 weeks prior to entry to the study plus optimal and stable medical treatment. Exclusion criteria were: unstable angina, congestive heart failure, uncontrolled hypertension, valvular heart disease.

\section{Study protocol}

At the beginning and after a cycle of trainings, each patient underwent exercise stress test (EST) and was scored on their ATT and AAL based on the Psychological Effects of Rehabilitation Score Scale (PERSS) according to Tylka and Makowska [14].

After initial investigation, patients underwent the training program (TP) started averagely 2 months after MI. The analysis covered:

- stress test findings: maximal workload in metabolic equivalents (METs), test duration (min) and physical capacity adjusted to sex and age (\%),

ATT and AAL based on PERSS,

return to professional work (RTW).

The study protocol was approved by the Institutional Ethics Committee on Human Research, and each participant gave their written informed consent.

\section{Exercise stress test}

All patients underwent symptom-limited EST performed on a cycle ergometer with the workload increased every 3 min by $50 \mathrm{~W}$ using a computerized system Case 8000 (Marquette Electronics, USA). A 3-lead ECG was monitored continuously before, during and for $10 \mathrm{~min}$ after the test. The test was discontinued in the case of fatigue, arterial blood pressure (BP) increase over 230/120 mm Hg, ST segment depression by at least $2 \mathrm{~mm}$ and/or angina. The test was considered positive when ST segment depression of at least $1 \mathrm{~mm}$ was horizontal or downsloping, $80 \mathrm{~ms}$ beyond the J point.

\section{Physical training}

Interval training was planned according to the guidelines on exercise prescription in patients with coronary artery disease [1]. Patients were qualified for TP on the basis of their EST results. The limit of the training heart rate (HR) was calculated as the sum of resting HR and $60-80 \%$ of $H R$ reserve, i.e., the difference between maximal and resting HR. All of them underwent 24 interval trainings on a cycle ergometer 3 times a week. Each training session lasted $40 \mathrm{~min}$ and included a 4 -min warm-up, six 4-min exercise bouts separated by 2-min rests in between with gradually increased workload until HR limit achieved during EST was reached. During each session ECG, HR and BP were measured at baseline, at the end of each interval, and at recovery. The training was documented by a written protocol.

\section{Psychological Effects of Rehabilitation Score Scale (PERSS)}

The questionnaire used for evaluation of patient's ATT and AAL consisted of 23 statements. The patient was asked for marking the category which reflects her or his acceptance of a given statement. Each answer was scored from 1 to 5 according to the established key. The results were translated into a 10 -pts scale. The attitude was assessed as negative if the patient achieved 1-3 pts on the scale and positive if she or he obtained 7-10 pts. The medium level was characterized by $4-6$ pts.

Negative ATT and ALL are characterized by denying symptoms of a disease and methods of its therapy. Moreover, by connecting the illness with the professional work it predisposes to withdrawal from professional and social life. On the other hand, positive ATT and ALL are characterized by realistic evaluation of the illness, acceptation of the recommended therapy, and the greater probability of returning to professional work [14].

\section{Statistical analysis}

The statistical analysis was performed using SAS statistical software (version 8.2, Cary NC, USA). All data was expressed as $\mathrm{M} \pm \mathrm{SD}$ or as percentage rates. Student's $\mathrm{t}$-test for matched pairs was used for comparing the parameters of a continuous type in the groups studied, when the distribution of variables did not differ significantly from the normal distribution; when it did, a non-parametric rank test was used. In order to assess the differences of categorized parameters in the groups, $\chi^{2}$ test was used when the number was high enough or Fisher's exact test when it was not significant. The association between AAL, ATT and RTW was assessed 
by means of Pearson's correlation coefficients. A p value $<0.05$ was considered statistically significant.

\section{RESULTS}

The clinical characteristics of the patients studied are listed in the Table 1. Most of them had hypertension and hypercholesterolemia. There were no differences between men and women in terms of age, coronary risk factors, clinical status, concomitant medication and employment status. Male patients were waiting for CR longer, however insignificantly longer than female patients. Exercise capacity improved significantly after TP in all patients studied, separately in men and in women. After CR was completed maximal workload assessed in METs during EST increased from $5.98 \pm 1.20$ to $6.77 \pm 1.14$ in the whole group $(\mathrm{p}<0.001)$, from $6.00 \pm 1.20$ to $6.84 \pm 1.22$ in men $(\mathrm{p}<0.001)$ and from $5.93 \pm 1.23$ to $6.64 \pm 0.98$ in women $(\mathrm{p}<0.05)$. In the whole group, an increase in EST duration amounted to $22 \%$ and for workload to $13 \%$ whereas in men - to $25 \%$ and $16 \%$, respectively, and in women - to $12 \%$ and $7 \%$, respectively. Exercise capacity adjusted to sex and age improved significantly to $12 \%$ in all patients studied whereas in men - to $12 \%$ and in women to $10 \%$, respectively (Figure 1). Attitude to the aims in life and professional work significantly increased in the whole group $(4.4 \pm 2.8$ vs. $5.1 \pm 2.4$, $\mathrm{p}<0.01)$ and separately in men $(4.5 \pm 2.9$ vs. $5.1 \pm 2.5$, $\mathrm{p}<0.05)$ and women $(4.3 \pm 2.6$ vs. $5.0 \pm 2.0, \mathrm{p}<0.05)$ (Figure 2). Attitude to the therapy did not change significantly in the whole group (5.6 2.8 vs. $6.0 \pm 2.8)$ and in men (5.9 \pm 2.9 vs. $6.0 \pm 2.9)$, but increased significantly in women (5.0 \pm 2.5 vs. $6.1 \pm 2.7, \mathrm{p}<0.05)$ (Figure 3$)$. Authors also assessed the relationship between AAL and ATT and RTW. After TP, a positive correlation between AAL and RTW $(r=0.41, p<0.05)$ and between ATT and RTW ( $\mathrm{r}=0.43, \mathrm{p}<0.05)$ was found in the male subgroup and in the whole group $(r=0.40, p<0.05)$. It should not be excluded that the lack of correlation in the female subgroup was caused by too small number of patients. Professional work was resumed, averagely by $86.4 \%$ of all patients $(85.7 \%$ men and $87.5 \%$ women, $\mathrm{p}=$ not statistically significant). It bears noting that all rehabilitated patients who had worked before MI returned to work.

Table 1. Clinical characteristics of the post-MI men and women rehabilitated in the ambulatory part of the Department of Cardiac Rehabilitation between January and December 2016

\begin{tabular}{|c|c|c|c|}
\hline Clinical characteristics & $\begin{array}{c}\text { Total } \\
(\mathrm{N}=44)\end{array}$ & $\begin{array}{c}\text { Men } \\
(\mathrm{N}=28)\end{array}$ & $\begin{array}{c}\text { Women } \\
(\mathrm{N}=16)\end{array}$ \\
\hline Age [years] $(\mathrm{M} \pm \mathrm{SD})$ & $58.0 \pm 10.0$ & $59.5 \pm 9.0$ & $54.8 \pm 8.0$ \\
\hline Hypertension [n (\%)] & $26(59.1)$ & $20(71.4)$ & $6(37.5)$ \\
\hline Type 2 diabetes mellitus [n (\%)] & $8(18.2)$ & $3(10.7)$ & $5(31.3)$ \\
\hline Time to cardiac rehabilitation [days] $(\mathrm{M} \pm \mathrm{SD})$ & $62.1 \pm 44.0$ & $64.1 \pm 52.7$ & $58.5 \pm 27.5$ \\
\hline LVEF [\%] & $53.4 \pm 8.8$ & $53.1 \pm 9.5$ & $54.1 \pm 7.7$ \\
\hline \multicolumn{4}{|l|}{ Medications [n (\%)] } \\
\hline$\beta$-blockers & $35(79.5)$ & $25(89.3)$ & $12(75.0)$ \\
\hline ticagrelol & $6(13.3)$ & $3(10.7)$ & $3(18.8)$ \\
\hline aspirin & $43(97.7)$ & $27(96.4)$ & $16(100)$ \\
\hline Professional work before MI [n (\%)] & $38(86.4)$ & $24(85.7)$ & $14(87.5)$ \\
\hline Mental work [n (\%)] & $20(45.5)$ & $13(46.4)$ & $7(43.7)$ \\
\hline Physical work [n (\%)] & $18(40.9)$ & $11(39.2)$ & $7(43.7)$ \\
\hline Pension [n (\%)] & $6(13.6)$ & $4(14.3)$ & $2(12.5)$ \\
\hline
\end{tabular}

ACEIs - angiotensin-converting enzyme inhibitors, LVEF - left ventricular ejection fraction, MI - myocardial infarction. For all results $\mathrm{p}$ is not statistically significant. 


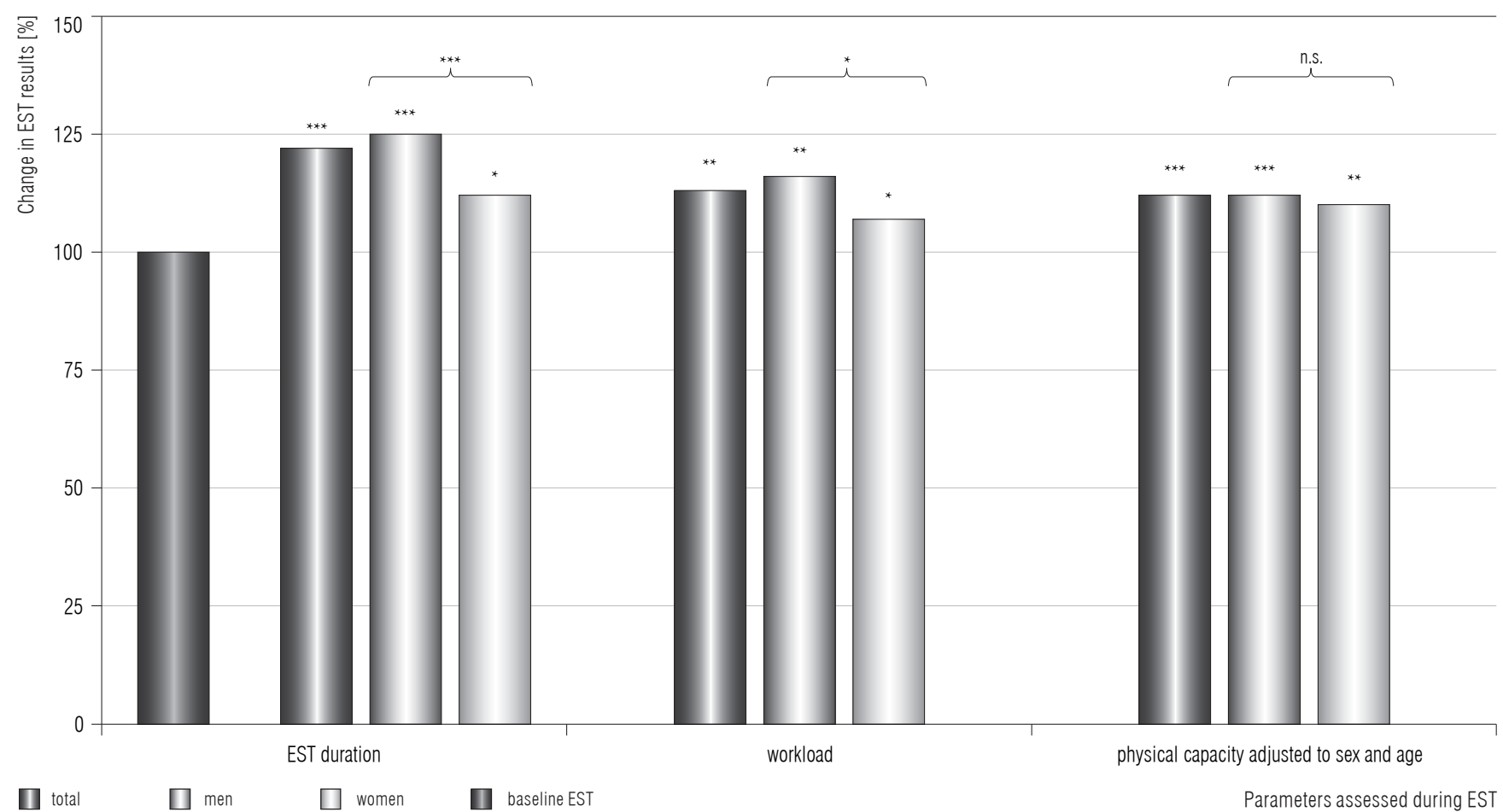

Percent changes from the baseline EST results are plotted. ${ }^{*} \mathrm{p}<0.05,{ }^{* *} \mathrm{p}<0.01,{ }^{* * *} \mathrm{p}<0.001$ vs. baseline.

Figure 1. Changes in the results of exercise stress tests (EST) in all studied patients $(\mathrm{N}=44)$ and separately in men $(\mathrm{N}=28)$ and women $(\mathrm{N}=16)$ before and after the training program

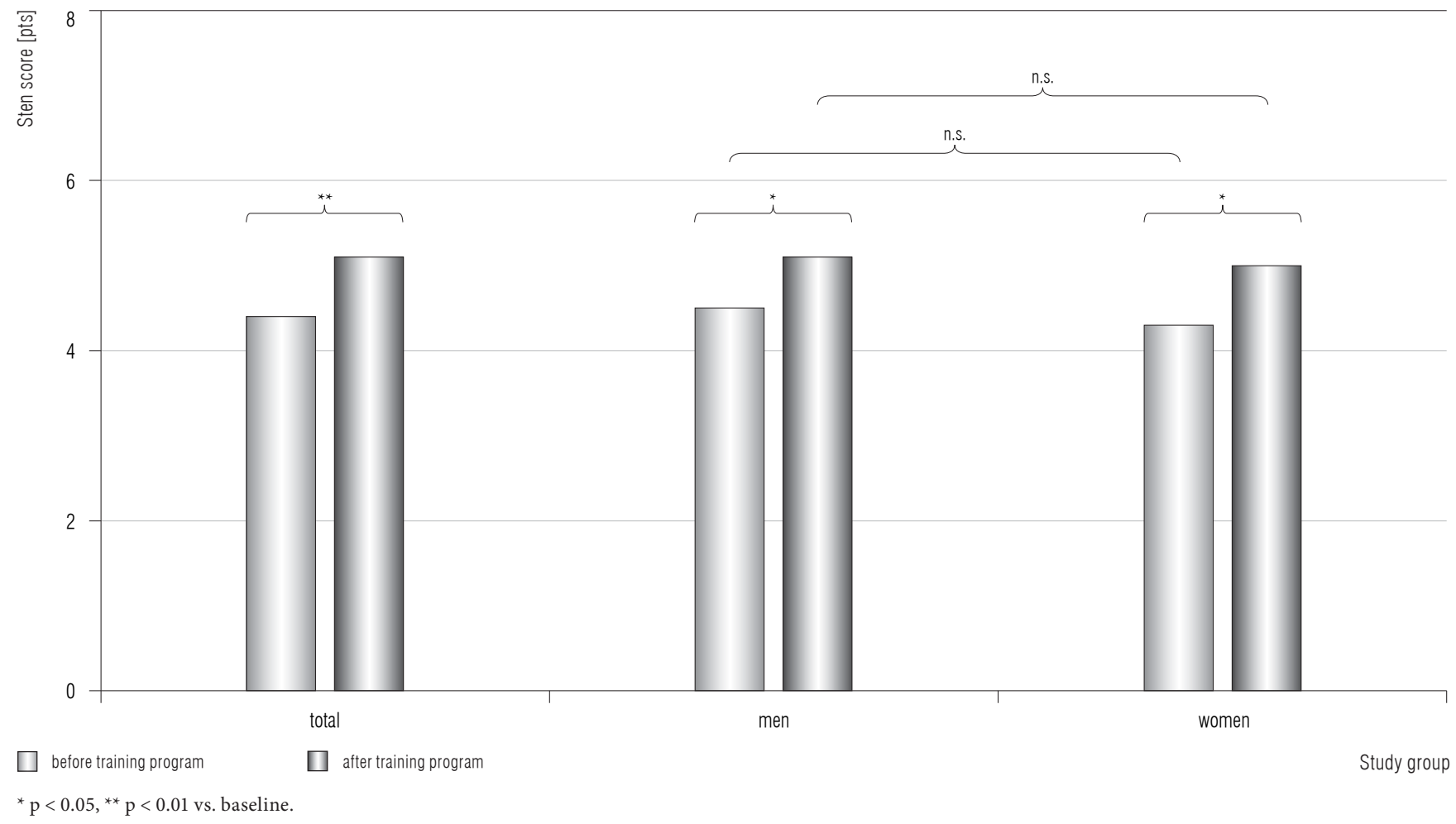

Figure 2. Attitude to aims in life and professional work in all studied patients $(\mathrm{N}=44)$ and separately in men $(\mathrm{N}=28)$ and women $(\mathrm{N}=16)$ before and after the training program 


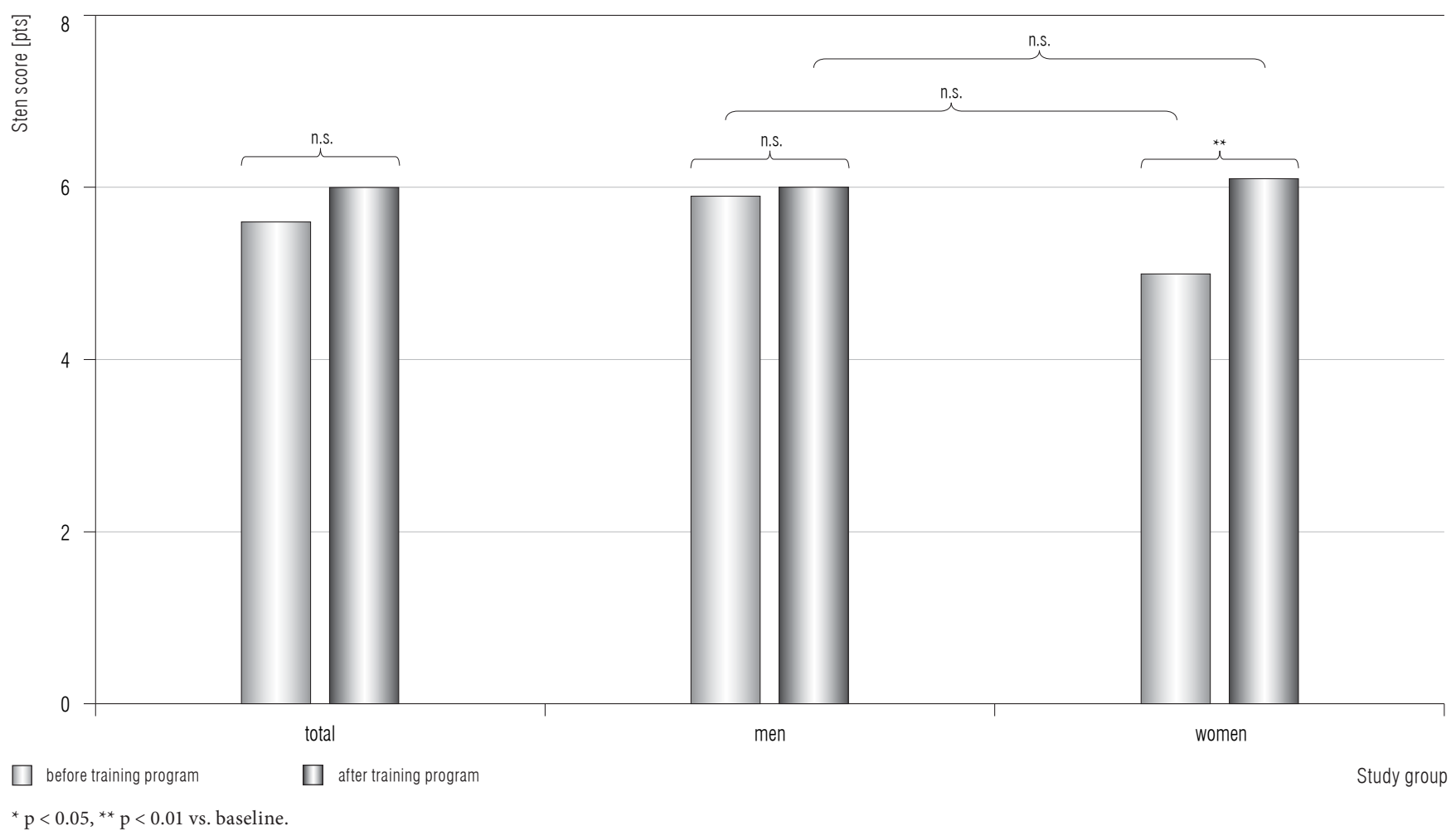

Figure 3. Attitude to the therapy (ATT) in all studied patients $(\mathrm{N}=44)$ and separately in men $(\mathrm{N}=28)$ and women $(\mathrm{N}=16)$ before and after the training program

\section{DISCUSSION}

To the best of our knowledge, this study was the first which assessed the influence of CR limited to physical training, without professional psychological intervention, on the self-care attitude in the heterogenous group of post-MI patients.

Authors considered ATT and AAL as important determinants of psychosocial well-being and found that a cycle of physical trainings improved AAL significantly in the whole group and separately in the male and female subgroups. Although, ATT did not change significantly in the whole group and in the male subgroup, it increased significantly in the female subgroup.

It has been established that self-care estimation plays an important role in defining patients' future plans on mental, physical and social activities [14]. Therefore, several elements of psychosocial well-being are considered for patients with various cardiovascular diseases, including those after MI. One of the previously published studies measured the self-image and self-care attitude and found a strong correlation between them in post-MI patients referred to comprehensive CR [15]. The authors have concluded that the level of self-acceptance may de- fine the degree of personal involvement in adjustment to life after MI. It should be emphasized, however, that they did not examine the significance of the above mentioned psychological factors on the efficacy of the CR process. In another study, Dragunajtys-Sudoł investigated psychological effects of a 24-day comprehensive CR for 170 patients with various cardiovascular diseases [16]. Using a common questionnaire constructed by Tylka and Makowska (PERSS) [14], she found that participation in CR with psychotherapy did not change the negative attitude to disease-specific behavior. Surprisingly, ATT and AAL deteriorated after CR, patients denied the need for preventive activities reducing cardiac risk, declared resignation from professional work. It is noteworthy, that negative self-estimation might be caused not only by a relatively short time of comprehensive CR, but also by a specific group of patients expected from CR to allow them to subsist without working. On the contrary, authors' physical training program significantly improved AAL in all patients and ATT in the female subgroup.

Moreover, professional work was resumed by $85.7 \%$ men and $87.5 \%$ women. It should be noted, that the training program started averagely 2 months after MI, lasted up to 3 months and caused significant improve- 
ment of exercise capacity for all patients. Apart from favorable changed psychosocial well-being authors observed a significant improvement in exercise capacity in all trained patients, including women. This needs to be brought to the attention of health care providers because CR remains largely underutilized in women [17].

Moreover, one should take into account that exercise capacity plays an important role when it comes to a patient's recovery to work. Maximal workload attained during exercise stress test could help the physician in assessing whether the patient would be able to resume professional activities. Taking into account that metabolic cost of the mental and light physical work attained below 5 METs, the average intensity of a daily work (6-8 h) should not exceed $40-50 \%$ of the maximal workload obtained during exercise stress test [6].

It is noteworthy that mean workload after CR in the whole group was found to be 6.77 \pm 1.14 METs (6.84 \pm 1.22 for men and $6.64 \pm 0.98$ for women) and allowed the patients to undertake professional labour.

Although, to date there were no CR programs comprising only physical training and assessing post-MI related behavior authors can only hypothesize that CR may promote positive heart-health life changes, including higher activity undertaken within self-care.

In summary, authors found that physical training as the basic element of CR not only resulted in significant improvement of exercise capacity, but also such determinants of psychosocial well-being like AAL in the whole group and separately in the male and female subgroups.

\section{CONCLUSIONS}

Physical training beneficially influenced post-MI men's and women's attitude to the aims in life, professional work and attitude to the therapy in women.

\section{Limitation}

The lack of a non-exercised control group is an acknowledged limitation of this study; however, at present it has been considered unethical to suggest that post-MI patients avoid physical activity. Moreover, small numbers of patients limit the generalizability of authors' results.

\section{REFERENCES}

1. Flechter GF, Ades PA, Kligfield P, Arena R, Balady GJ, Bittner VA, et al. Exercise standards for testing and training: A statement for healthcare professionals from the American
Heart Association. Circulation. 2013;128:873-934, https:// doi.org/10.1161/CIR.0b013e31829b5b44.

2. Leon AS, Franklin BA, Costa F, Balady GJ, Berra KA, Stewart KJ, et al. Cardiac rehabilitation and secondary prevention of coronary heart disease: An American Heart Association scientific statement from the Council on Clinical Cardiology and the Council on Nutrition, Physical Activity, and Metabolism, in collaboration with the American Association of Cardiovascular and Pulmonary Rehabilitation. Circulation. 2005;111:369-76, https://doi.org.10.1161/01. CIR.0000151788.08740.5C.

3. Piepoli MF, Corra U, Benzer E, Bjarnason-Wehrens B, Dendale P, Gaita D, et al. Secondary prevention through cardiac rehabilitation: From knowledge to implementation. A position paper from the Cardiac Rehabilitation Section of the European Association of Cardiovascular Prevention and Rehabilitation. Eur J Cardiovasc Prev Rehabil. 2010;17:1-17, https://doi.org/10.1097/HJR.0b013e3283313592.

4. Taylor RS, Brown A, Ebrahim S, Jolliffe J, Noorani H, Rees K, et al. Exercise-based rehabilitation for patients with coronary heart disease: Systematic review and meta-analysis of randomized controlled trials. Am J Med. 2004;116:682-92, https://doi.org/10.1016/j.amjmed.2004.01.009.

5. Korzeniowska-Kubacka I, Bilińska M, Stepnowska M, Piotrowska D, Piotrowicz R. The impact of exercise only-based rehabilitation on depression and anxiety in patients after myocardial infarction. Eur J Cardiovasc Nurs. 2017;16(5):390-6.

6. Korzeniowska-Kubacka I, Piotrowicz R. [Cardiological rehabilitationa chance of returning to work]. Med Pr. 2005; 56(4):325-7. Polish.

7. Boudrez $H$, de Backer G. Recent findings on return to work after an acute myocardial infarction or coronary artery bypass grafting. Acta Cardiol. 2000;55(6):341-9, https://doi. org/10.2143/AC.55.6.2005765.

8. Isaaz K, Coudrot M, Sabry MH, Cerisier A, Lamaud M, Robin $\mathrm{C}$, et al. Return to work after acute ST-segment elevation myocardial infarction in the modern era of reperfusion by direct percutaneous coronary intervention. Arch Cardiovasc Dis. 2010;103(5):310-6, https://doi.org/10.1016/ j.acvd.2010.04.007.

9. Kleniewska A, Ojrzanowski M, Lipińska-Ojrzanowska A, Wiszniewska M, Walusiak-Skorupa J. [Barriers to professional activity among people with cardiovascular diseases]. Med Pr. 2012;63(1):105-15. Polish.

10. Slebus FG, Jorstad HT, Peters RJG, Kuijer PFM, Willems JH, Sluiter JK, et al. Return to work after acute coronary syndrome: Patients' perspective. Saf Health Work. 2012;3(2): 117-22, https://doi.org/10.5491/SHAW.2012.3.2.117.

11. Bhattacharyya MR, Perkins-Porras L, Whitehead DL, Steptoe A. Psychological and clinical predictors of return to work 
after acute coronary syndrome. Eur Heart J. 2007;28(2): 160-5, https://doi.org/10.1093/eurheartj/ehl440.

12. Ceyda S, Demiral Y, Kilic B, Aslan O. Changes in employment status after myocardial infarction among men. Balkan Med J. 2016;33(4):419-25.

13. Budnick K, Campbell J, Esau L, Lyons J, Rogers N, Haennel RG. Cardiac rehabilitation for women: Systematic review. Can J Cardiovasc Nurs. 2009;19:13-25.

14. Tylka J, Makowska M. [Psychological Effects of Rehabilitation Score Scale (PERSS)]. Przegl Psychol. 1985;28(3): 815-23. Polish.
15. Wilski M. [Selfe-image after myocardial infarction and selfcare attitude]. Psychiatr Psychol Klin. 2011;11(1):15-25. Polish.

16. Dragunajtys-Sudoł M. [Psychological effects of cardiac rehabilitation in sanatorium center]. Folia Cardiol Excerpta. 2009;4(5):291-5. Polish.

17. Sanderson BK, Shewchuk RM, Bittner V. Cardiac rehabilitation and women: What keeps them away? J Cardiopulm Rehabil Prev. 2010;30(1):12-21, https://doi.org/10.1097/ HCR.0b013e3181c85859.

This work is available in Open Access model and licensed under a Creative Commons Attribution-NonCommercial 3.0 Poland License - http://creativecommons.org/licenses/by-nc/3.0/pl/deed.en. 